\title{
From the editors
}

\section{Celebrating a milestone}

This is a difficult editorial to write. Our intent originally was to celebrate this issue as signaling a key milestone in the history of the journal inasmuch as it is the first in what is our 2oth year. However, our celebratory instincts have been somewhat muted by the worldwide pandemic caused by the Coronavirus. Let us elaborate on both points.

First, as to the anniversary, we have to say that when the journal was founded in 2000, with the appearance of volume 1 in the fall of that year, the four founding co-editors-Gaberell Drachman, Geoffrey Horrocks, Brian Joseph, and Irene Philippaki-Warburton - had great aspirations, to be sure, but could not foresee that the journal would have a successful run of 20 years, leading to the current issue. In fact, there was a bleak period, in 2008, when our first publisher, John Benjamins, decided to end their support of the journal; as a result, the journal was severely endangered and was left scrambling for a new home. It was only the willingness of Brill Publishers to take on the journal that led, with a one-year hiatus (i.e., no journal in 2008), to the continuous record of publication that the Journal of Greek Linguistics (JGL) now displays, bringing us to the present issue. The switch to Brill has also led to our having two issues per year (versus one under Benjamins) and has allowed for occasional special issues dedicated to a single theme. Moreover, as of 2016, JGL is now published in Open Access.

Several of the reasons that the then-editors gave in 2000 justifying the creation of a journal dedicated to Greek linguistics are as valid now as they were 20 years ago. In the first "From the Editors" statement about the journal (Drachman et al. 2000), the editors cited the growth in the field of Greek linguistics, pointing to such indicators as institutional expansion in the form of new or newly reconstituted linguistics sections within university departments in Greece itself, the biennial International Conference on Greek Linguistics (ICGL), publication of basic works such as thorough descriptive grammars, and a steady stream of dissertations on Greek from scholars in various universities. Such growth has continued since 2000 and it is reflected in the journal itself: Joseph et al. 2019 documents further institutional growth in Greek studies and our many dissertation summaries (e.g. Bianconi 2020, in this issue) and our occasional Brief Notices and Recent Publications listings reflect the continu- 
ing scholarship in the field, including new basic works such as dictionaries (e.g. Charalambakis 2014) and dialect descriptions (e.g. Katsoudas 2016) as well as the long-awaited monumental grammar of Medieval Greek (Holton et al. 2019). And conferences have shown continued expansion: ICGL has now met 14 times with ICGL 15 planned for 2021, and the Modern Greek Dialects and Linguistic Theory conference (MGDLT), which was a fledging operation that had met for the first time only in 2000, has its ninth instantiation planned for later this year.

Of course, such plans must now be tempered by the specter of covid-19 and the Coronavirus that causes it. Life has changed dramatically in the past three months and just as things that we all took for granted, the cup of coffee or lunch with friends, the family gatherings, and so on, are a thing of the past now, so too with things that academics once took for granted, such as fieldwork and also conferences and the spontaneous interactions that sparked our scholarship. But we can, in a sense, continue to take refuge in our scholarship and the exchange of ideas and data and analyses that the medium of outlets like our journal can foster. In an era where face-to-face meetings are restricted, journals become all the more important as venues for advancing knowledge. So we have yet another justification, a grim one to be sure, for celebrating the existence and continued vitality of $J G L$.

We realize that in this era, our ability to maintain the journal even under difficult life circumstances is made possible through the work of those valiant souls who provide essential societal services, medical and otherwise, and thereby allow us to continue our scholarship despite our current state of being homebound. Accordingly, we salute them and we dedicate this issue to them.

Dag T.T. Haug, Brian D. Joseph, and Anna Roussou 27 April 2020

\section{References}

Bianconi, Michele. 2020. Dissertation summary: The Linguistic Relationships between Greek and the Anatolian Languages. Journal of Greek Linguistics 20.

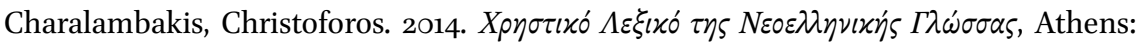
Academy of Athens.

Drachman, Gaberell, Geoffrey Horrocks, Brian Joseph, \& Irene Philippaki-Warburton. 2000. From the editors. Journal of Greek Linguistics 1: 1-8.

Holton, David, Geoffrey Horrocks, Marjoline Janssen, Tina Lendari, Io Manolessou, \& Notis Toufexis. 2019. The Cambridge Grammar of Medieval and Early Modern Greek. 
Volume 1: General Introduction \& Phonology, Volume 2: Nominal Morphology, Volume 3: Verb Morphology, Volume 4: Syntax. Cambridge: Cambridge University Press.

Joseph, Brian D., Anastasia Giannakidou, Stefanos Katsikas, Ianthi Tsimpli, and Tim Whitmarsh. 200o. Institutional Developments in Greek Linguistics. Journal of Greek Linguistics 19: 215-226.

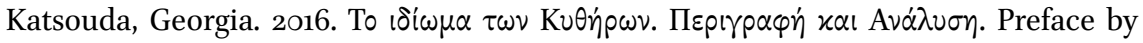
Angeliki Ralli. Athens: Etaireia Kytheriakon Meleton. 